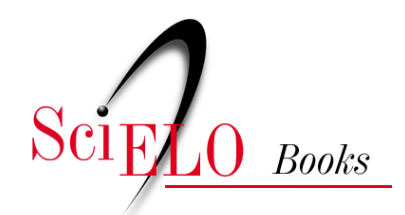

\title{
Apresentação \\ A mobilização social rural no sul do Brasil: perspectivas de análise
}

\author{
João Carlos Tedesco \\ Jonas José Seminotti \\ Humberto José da Rocha \\ (orgs.)
}

TEDESCO, J.C., SEMINOTTI, J.J., and ROCHA, H.J., ed. Apresentação - A mobilização social rural no sul do Brasil: perspectivas de análise. In: Movimentos e lutas sociais pela terra no sul do Brasil: questões contemporâneas [online]. Chapecó: Editora UFFS, 2018, pp. 6-27. ISBN: 978-85-64905-76-4.

https://doi.org/10.7476/9788564905764.0001.

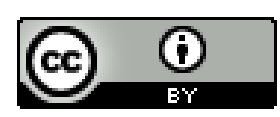

All the contents of this work, except where otherwise noted, is licensed under a Creative Commons Attribution 4.0 International license.

Todo o conteúdo deste trabalho, exceto quando houver ressalva, é publicado sob a licença Creative Commons Atribição $\underline{4.0}$.

Todo el contenido de esta obra, excepto donde se indique lo contrario, está bajo licencia de la licencia $\underline{\text { Creative Commons }}$ Reconocimento 4.0. 


\title{
Apresentação A mobilização social rural no sul do Brasil: perspectivas de análise
}

\author{
João Carlos Tedesco ${ }^{1}$ \\ Jonas José Seminotti ${ }^{2}$ \\ Humberto José da Rocha ${ }^{3}$
}

A mobilização social de luta pela terra e por políticas públicas para o campo no sul do Brasil desenvolveu-se mais intensamente seguindo o histórico de resistência e luta dos povos indígenas, quilombolas e camponeses a partir da segunda metade do século XX, período marcado pelo fim da Segunda Guerra Mundial e pela bipolarização ideológica entre as duas maiores potências mundiais (Estados Unidos - capitalista e União Soviética - socialista), bem como por transformações dos paradigmas do desenvolvimento agrário brasileiro.

O Brasil, economicamente, vivia a égide da "ideologia desenvolvimentista", que correspondia a uma orientação econômica de industrialização pela iniciativa privada, porém planejada pelo Estado, que captava e orientava os recursos financeiros. O desenvolvimentismo abrangeu o período

\footnotetext{
1 Professor Adjunto da Universidade de Passo Fundo (UPF). Contato: <jctedesco@upf.br >.

2 Professor Adjunto da Universidade Federal do Rio Grande do Sul (UFRGS). Contato: <jonas.seminotti@ufrgs.br>.

3 Professor Adjunto da Universidade Federal da Fronteira Sul (UFFS). Contato: <humberto.rocha@uffs.edu.br>.
} 
de 1930-1980, com início no governo Vargas, destacando-se fortemente no governo Juscelino Kubitschek (1956-1961) e manteve sequência nos governos militares (1964-1985), que deram continuidade a essa orientação econômica. Do ponto de vista político, houve uma alteração no que diz respeito ao fluxo e refluxo dos direitos civis, políticos e sociais. O Ato Institucional $\mathrm{n}^{\circ} 5$ (AI 5), de 13 de dezembro de 1968, restringia a liberdade dos cidadãos brasileiros em quase todos os campos, levando a que a construção da cidadania não acompanhasse da mesma forma o ritmo desenvolvimentista. Porém, em 13 de outubro de 1978, o AI 5 foi revogado, e a nação brasileira começava a respirar um pouco mais livre.

Nesse contexto, em nível estrutural, considerando as duas orientações ideológicas da época (capitalismo e socialismo), tem-se o marco metodológico de predomínio do capitalismo multinacional, posição ideológica brasileira, em detrimento ao nacionalismo estatizante, representado pelas reformas de base do ex-presidente João Goulart. Interessava ao governo brasileiro o crescimento econômico global, de maneira que não viesse primeiro em benefício da sociedade brasileira, tanto que o ministro do período militar assim justificava: "Primeiro fazer o bolo crescer para depois dividi-lo".

Em 1945, final da Segunda Guerra Mundial, entrou em curso a chamada revolução verde, uma iniciativa de empresas norte-americanas que propagavam a modernização da agricultura mundial mediante a intensificação da mecanização e do uso de adubos e defensivos químicos. A partir da década de 1960, a proposta de modernização da agricultura chegou ao Brasil, instalando indústria pesada voltada para a industrialização da agricultura, com instalação de fábricas de máquinas e insumos. Já o reflexo se fez sentir, e o governo brasileiro criou a demanda para essa indústria. O resultado foi um aumento da concentração fundiária e uma rápida expansão da fronteira agrícola. A modernização prevaleceu no Centro-Sul e Nordeste, sendo que a fronteira agrícola se expandiu principalmente para o Norte (Amazônia) e Centro-Oeste (Mato Grosso e Goiás). 
A política de modernização agrícola interferiu também nas fronteiras das terras indígenas, caracterizando conflitos com os autóctones. Para resolver a questão, o governo criou o Serviço de Proteção ao Índio (SPI), mais tarde substituído pela Fundação Nacional do Índio (Funai) sem, contudo, mudar a orientação política desenvolvimentista. A ação do SPI foi, inicialmente, de natureza humanista, assumida, para proteger os índios, pelos irmãos Vilas Boas e pelo marechal Rondon. A política desenvolvimentista nacional, a partir de 1950, deu lugar a ações modernizantes, adotadas também em relação aos indígenas no sentido de tornar as áreas produtivas no limite em exportadoras de produtos. Na década de 1970, já como Funai, as ações foram norteadas a partir de projetos de integração dos índios com a sociedade via mecanização agrícola das terras e do arrendamento para os colonos.

A iniciativa dos arrendamentos agravou o problema de intrusão das terras indígenas pelos colonos, apesar de acontecer desde iniciativas colonizadoras do século XIX. Por meio desses arrendamentos avançavam além das áreas estabelecidas pelos contratos. Disso resultou em conflito entre agricultores e índios, o que aumentou a emergência do Movimento dos Agricultores Sem Terra (Master) a partir de 1961. Dentre as ações, o Master ocupou reservas indígenas como estratégia para pressionar a reforma agrária, o que gerou a reação dos índios no sentido de expulsar os intrusores.

Outro aspecto dessa opção de industrialização se reforçou na crise do petróleo em 1973, no sentido de ratificar a opção brasileira pela matriz hidrelétrica na geração de energia. Em resposta à crise, o governo passou a intensificar a instalação de usinas hidrelétricas (UHE), tanto que, para o setor elétrico, a década de 1970 foi conhecida como década ganha, pois se construíram grandes hidrelétricas, como Paulo Afonso, Três Marias, Furnas, Itaipu, Sobradinho, Tucuruí, Salto Osório e Salto Santiago, além da UHE Passo Real, elemento importante para a análise sobre o sul do Brasil. Considerando a hidroeletricidade como um processo social, partindo da primeira hidrelétrica instalada no Brasil (1883), pode-se dizer que até 
1970 e 1980 não havia um planejamento prévio para reassentamento das famílias atingidas por barragens. O remanejamento acontecia às vésperas ou quase que simultaneamente ao alagamento, conforme ocorreu na Sobradinho e Itaparica (rio São Francisco-PE), em 1970, e Tucuruí (rio Tocantins-PA) e Itaipu (rio Paraná-PR), em 1980.

Na segunda metade da década de 1970, o crescimento econômico, sustentado por empréstimos externos contraídos pelos governos militares, começou a dar sinais de crise. Não obstante ao mencionado crescimento dos índices econômicos, os reflexos tanto da modernização agrícola quanto da instalação de hidrelétricas não têm no aspecto social o mesmo desempenho que o econômico, já que as populações rurais passaram a ser gradativamente expulsas das suas terras por conta do avanço das duas iniciativas desenvolvimentistas.

Ante essa crise econômica, o governo militar já não tinha argumentos para sustentar a repressão dos direitos civis e políticos e a reação popular deflagrada. Iniciativas para a criação do Partido dos Trabalhadores (1980), o sindicalismo combativo (no campo e cidade), a orientação da Igreja Católica na linha da teologia da libertação e as organizações de classe (associações de professores, médicos, funcionários públicos, artistas) davam sinais de reação popular ante a conjuntura. Em outubro de 1978, a revogação do AI 5 significou um passo importante para a organização popular, com a volta dos exilados e a reorganização da classe política brasileira.

Nesse panorama histórico, mesmo que sucinto, é possível perceber que o desenvolvimentismo que impulsionou o campo econômico refletiu negativamente no social, já que os indicadores não incidiam necessariamente na qualidade de vida da população. A precariedade material ficou insuportável por conta das violações dos direitos humanos durante os governos militares.

As mobilizações sociais de contestação e resistência não são exclusividade do período desenvolvimentista; podem ser percebidas ao longo da história brasileira. Com olhar voltado para a formação da cidadania, 
Maria da Glória Gohn (2012) mapeou as principais lutas e movimentos sociais desde o século XIX, quando as lutas esparsas pelo território brasileiro pautavam questões como escravidão, tributos, poder público, regime político ou lutas entre categorias econômicas e pequenos camponeses até o século XX. Com o avanço da democracia e da complexidade das relações sociais, as pautas apresentaram-se mais difusas e os atores envolvidos apresentaram questões no sentido dos direitos humanos.

Gohn (2012) assinala vários movimentos: de estudantes, guerrilha (Araguaia, nordeste), comunidades eclesiais de base e pastoral da terra, sindicatos, classes (educação, saúde); lutas pela redemocratização e protestos pontuais (passagem de ônibus, indígenas, custo de vida); de Formoso e Trombas (Goiás); ligas camponesas a partir de Pernambuco desde 1950 e União dos Lavradores e Trabalhadores Agrícolas do Brasil (Ultab), fundada em São Paulo em 1954. Todos fundamentais para a compreensão do processo histórico das lutas pela terra.

Quanto à importância e à relação mútua entre as lutas e os movimentos para a compreensão do processo social, convém considerar a formação socioeconômica do sul do Brasil - Rio Grande do Sul, Santa Catarina e Paraná -, onde há traços comuns que os identificam. Um primeiro traço é o longo período de isolamento da vida política e a tardia incorporação à economia nacional. A colonização ocorreu com imigrantes oriundos das Colônias Velhas do Rio Grande do Sul no final do século XIX, chegando ao Oeste catarinense em 1930 e alcançaram o Paraná em 1950. As pequenas propriedades de agricultura familiar avançaram sobre áreas antes ocupadas por indígenas e caboclos. A economia de subsistência foi influenciada pela orientação capitalista internacional, baseada na propriedade privada da terra e no ethos do trabalho, fundamentado em valores comunitários e religiosos.

Os aspectos geográficos predominantes na região Sul eram vistos na contramão das iniciativas desenvolvimentistas dos governos brasileiros. Para além de índios e caboclos expropriados no ciclo anterior de colonização, a modernização da agricultura empreendida a partir da década de 
1960 atingiu também os pequenos agricultores familiares que se viram excluídos do processo por terem propriedades de pouca extensão e em áreas de relevo acidentado, o que dificultava a mecanização. Essa pressão tecnológica refletiu tanto na política indigenista, no sentido da "integração" ao capitalismo, como na pressão que os agricultores exerceram sobre as terras indígenas. Diante dessa situação, o fator geográfico ganhou importância pelo alto potencial à exploração hidrelétrica em razão dos vales dos rios Paraná, Iguaçu e Uruguai e seus afluentes. A conformação socioeconômica (espírito capitalista, propriedade privada da terra, ethos do trabalho, busca de riqueza) e cultural (valores comunitários e religiosos) resultante do modelo de colonização predominante nessas áreas foi outro elemento que condicionou a região a um potencial berço de movimentos de contestações. A partir desse cenário, os movimentos e as lutas sociais pela terra corresponderam tanto à modernização agrícola quanto à instalação de hidrelétricas. A iniciativa de contestações foi a partir de movimentos de pequenos agricultores da agricultura familiar sem-terra atingidos por barragens, indígenas, quilombolas e mulheres camponesas que emergiram no local a partir desse projeto modernizante intensificado na década de 1960.

O sul do Brasil pode ser tomado como palco da mobilização social em vista da estrutura mundial e conjuntura brasileira a partir da década de 1960. A expressão “mobilização social” reclama uma conotação histórica. De acordo com Charles Tilly (1977), o termo define-se como "processo pelo qual um grupo passa de um coletivo passivo de indivíduos a um grupo participativo na vida pública”. A mobilização implica que o grupo passa a ter controle sobre os recursos de cunho repressivo (armas), utilitário (dinheiro, materiais) e normativo (obrigações) que até então não controlava.

Para entender em que condições essa mobilização desponta, parte-se do conceito de polity model que Tilly (1977) desenvolve para tratar das condições de mobilização a partir do exterior do grupo que se mobiliza, considerando os elementos "governo", "população" e "outros grupos" 
concorrentes ou aliados. Resgatando a análise conjuntural apresentada anteriormente, basta assinalar que o governo brasileiro imprimia uma política desenvolvimentista que desfavorecia a maior parte da população do campo, especialmente na fronteira sul do Brasil.

No elemento "grupo", não obstante, já se realizavam conferências de trabalhadores rurais organizadas pelo $\mathrm{PCB}$, além de registros de confrontos entre posseiros e policiais militares na reivindicação de terras em alguns lugares do Sul. Esses movimentos isolados ainda não caracterizavam um grupo ou movimento coeso, porém apontavam o surgimento deles, tomando corpo e agravando-se pela crescente concentração da propriedade da terra e o esgotamento da fronteira agrícola no Rio Grande do Sul.

O cenário de restrições desenvolvimentistas e mobilizações remetem à ideia de Sidney Tarrow (2009) acerca dos “ciclos de confrontos”. Um ciclo é notabilizado por um ou mais eventos de culminância que ajudam a catalisar os elementos dispersos, porém interligando-se ao longo do processo social correspondente. $\mathrm{O}$ autor define ciclo como "uma fase de conflito acentuado que atravessa um sistema social", caracterizado por "uma rápida difusão da ação coletiva de setores mais mobilizados para outros menos mobilizados", pela "criação de quadros interpretativos de ação coletiva, novos ou transformados", pela "combinação de participação organizada e não organizada”, pela capacidade de produzir "externalidades que dão aos desafiantes ao menos uma vantagem temporária e permite que superem a fraqueza na sua base de recursos". Um ciclo de confronto "produz resultados gerais que são mais do que a soma dos resultados de um agregado de eventos desconectados", compreende um período em que as restrições e reações se acentuam de tal forma que conformam uma unidade de análise (TARROW, 2009).

Nessa perspectiva, os ciclos de confrontos podem ser vislumbrados no Brasil, especialmente no Sul, a partir do surgimento do Movimento dos Agricultores Sem Terra (Master) na década de 1960. 
A linha de raciocínio de Tilly (1977), do ponto de vista do interior do grupo, utiliza o conceito de mobilization model e elenca cinco aspectos para a análise das possibilidades de mobilização: interesse, vantagens ou desvantagens comuns que possam advir para a população em questão; organização, medida da identidade comum que unifica os indivíduos da população; mobilização, quantidade e qualidade de recursos no controle do grupo; ação coletiva, grau da ação conjunta do grupo no processo de busca de fins comuns; oportunidade, sintonia entre os interesses do grupo, da população e do estado atual do mundo em torno dele.

O Master, ao reunir desempregados, posseiros, parceiros, arrendatários, agregados e pequenos proprietários, deve ser relacionado ao perfil socioeconômico da região para assinalar a fragilidade ante a política desenvolvimentista da modernização agrícola, deixando clara a sintonia com os interesses e a identificação da mobilização com a população do campo. A modernização e o esgotamento da fronteira agrícola colocaram os pequenos agricultores num dilema: migrar para outras regiões ou para a cidade, ou, ainda, intrusar terras indígenas. O apoio do governo do Rio Grande do Sul, com base na ideia de que havia muita terra para pouco índio, passou a incentivar e legitimar a intrusão de agricultores nas reservas indígenas. Essa ação pode ser entendida como consequência da política desenvolvimentista brasileira e que, mais tarde, refletiria no surgimento de outros conflitos de luta pela terra na região.

Quanto aos outros elementos da análise de Tilly (1977) sobre o mobilization model -mobilização, ação coletiva e oportunidade -, apesar do apoio do governo do Rio Grande do Sul, a organização da luta pela terra pode ser considerada incipiente até os primeiros anos de 1960. Não se tem a pretensão de aprofundar a história do Master, mas assinalar a correspondência entre o surgimento do movimento e a conjuntura e assinalar, como ponto fundamental, a primeira ocupação, em 1962, na Fazenda Sarandi, feita pelo então fundado Master. Além de considerar um marco histórico da luta pela terra, a ocupação significa o primeiro e talvez o mais 
importante elemento constituinte do que Charles Tilly (1977) chama de "repertório" da luta pela terra. Genericamente o termo refere-se às formas como o grupo utiliza os recursos que passa a dispor (repressivos, utilitários, normativos) no contexto da mobilização. $\mathrm{O}$ autor assinala que o repertório de um grupo é conformado pelas circunstâncias do momento, que também tendem a evoluir segundo a trajetória da mobilização.

Passados mais de cinquenta anos da ocupação da fazenda, sabemos que a luta pela terra compreende desde ações de conscientização a debates acerca da questão, enfrentamentos físicos e manifestações. De qualquer forma, o que ficou marcado desde o início foi a ocupação como carro-chefe de mobilização.

O repertório de uma mobilização em determinado ciclo de confronto acontece em virtude de condições internas e externas ao grupo. Um ponto não mencionado, que também caracteriza o conjunto, é o ciclo de protestos e o respectivo repertório de mobilização, levando a que o Estado monte amplas estratégias de reação, repressivas ou facilitadoras, ou uma combinação de ambas. Na maioria das vezes, sobretudo no Brasil, na década de 1960, a mobilização social correspondeu a uma reação às políticas de governo. Todavia, a medida da repressão ou facilitação do governo ante a mobilização é um elemento crucial. Não significa que a mobilização social está condicionada à vontade do governo, mas a medida da repressão/ facilitação influencia no custo da mobilização. Nesse sentido, a tomada do governo federal pelos militares, com o consequente fim do governo Brizola e a posse de Ildo Meneghetti pelo Partido Social Democrático (PSD) no governo gaúcho, em 1963, representou o endurecimento da repressão estatal com a total ausência de assentamentos dos sem-terra de 1964 a 1979, iniciando, assim, uma nova etapa de luta pela terra na região Sul.

Tilly (1977) destaca que a comunicação e a criminalização são elementos que o Estado pode controlar de forma a reprimir ou facilitar a mobilização social. O autor deixa claro que um governo necessariamente não precisa ser compreendido como repressivo ou facilitador. Os governos, na 
maioria das vezes, combinam ambas as partes e agem de forma seletiva, segundo suas intenções. No governo Brizola, por exemplo, o que era tido como favorável aos agricultores não tinha a mesma conotação na perspectiva indígena. Já no governo Meneghetti, a repressão e a contrainformação praticamente inviabilizaram a mobilização social no período de 1964 a 1979, embora grandes madeireiros, granjeiros, industriais e comerciantes regionais tenham sido beneficiados.

No conjunto da análise é importante relacionar a narrativa histórica e os elementos teóricos para obter pistas de como aconteceu a mobilização social de luta pela terra a partir da polity model desenvolvimentista. $\mathrm{O}$ agravamento da situação, especialmente no campo econômico, fez emergir um ciclo de confronto em que a mobilização social, marcada pela formação do Master no início da década de 1960, deixa perceber que o principal recurso do repertório era a ocupação de terra. Consequentemente, o governo reage à mobilização e reprime a luta pela terra. Esse período de inanição da luta foi também de aglutinação de forças que viriam eclodir futuramente num outro ciclo de protestos, quando a luta pela terra se estabeleceu como eixo aglutinador de diferentes grupos.

A ocupação e o decreto de desapropriação da Fazenda Sarandi foram marcos importantes de luta por mostrar o poder de mobilização social. Contudo, a mudança conjuntural no Rio Grande do Sul e os "anos de chumbo" da ditadura militar colocariam à prova tal mobilização, sendo que novos elementos passaram a constituir um ciclo de confronto, de forma que uma "indústria de movimentos sociais", no sentido proposto por McCarthy e Zald (1977), pode ser percebida na época. Os autores fazem a análise na perspectiva da mobilização de recursos e acrescentam ideias que ajudam a compreender essa fase de luta pela terra. Partindo da ideia genérica de movimento social enquanto conformação de um conjunto de opiniões e crenças que buscam mudanças em alguns elementos estruturais ou distribuição de recompensas de uma determinada sociedade, os autores explicam que esse movimento social não aparece espontaneamente. 
Corresponde a uma "organização complexa e formal, que identifica suas metas com as preferências de um movimento ou mesmo de um contramovimento, e tenta implementar essas metas" (Social Movement Organization - SMO). Assim, um movimento social mobiliza recursos para organizar-se. Na sequência do raciocínio, os autores chegaram ao conceito de indústria de movimentos sociais (Social Movement Industry - SMI), quando diferentes movimentos sociais procuram identificar-se com um maior número de preferências e objetivos em relação a outros movimentos (MCCARTHY; ZALD, 1977).

Essa "indústria" (SMI) teve na própria política desenvolvimentista brasileira uma importante fornecedora de matéria-prima. A partir da segunda metade da década de 1960 começaram os trabalhos de instalação da usina hidrelétrica Passo Real, no rio Jacuí-RS, que implicaria o remanejamento populacional das famílias atingidas. Em março de 1972, o Incra deu início ao processo de desapropriação da Fazenda Annoni para reassentar parte dessas famílias, o que foi interrompido por conta da judicialização dos proprietários das terras, desencadeando um processo de luta dos atingidos. Diante disso, a Usina Passo Real forneceria outro substrato para a chamada "indústria de movimentos sociais" na fronteira sul. Além dos agricultores sem-terra, em razão da modernização agrícola, os projetos de grande escala a partir da inundação de milhares de hectares despejavam mais outra leva de agricultores que, pela natureza da perda, ficaram conhecidos como afogados do Passo Real.

A relação entre os conceitos de ciclos de protestos e SMI ajuda a compreender como a mobilização social foi ganhando unidade com o passar do tempo, apesar da repressão estatal a partir de 1964. Para avançar no entendimento de qual seria o eixo dessa unidade, o conceito de frames, elaborado por David A. Snow e Robert D. Benford (1992) a partir dos conceitos anteriores, torna-se importante. A palavra frame remete à ideia de "quadro" ou "moldura", que, metaforicamente, sugere "um esquema interpretativo que simplifica e condensa o mundo lá fora, pontuando 
seletivamente e codificando objetos, situações, eventos, experiências e sequências de ações dentro do ambiente presente ou passado". Segundo os autores, num cenário de ação coletiva, a importância de um frame está na capacidade de atribuição e articulação. Na esfera da atribuição, a referência de um frame ajuda nos diagnósticos (identificação) e prognósticos (resolução) de problemas. Já na esfera da articulação, funciona no sentido de alinhar elementos para constituir uma ordem significativa, o que seria buscado entre os grupos que demonstram uma "consciência aderente".

Assim, o conceito de frame aproxima-se do SMO por fazer referência a um grupo específico que busca atribuição e articulação no mundo social. No caso citado, o Master procurou reunir pessoas que de certa forma perderam suas terras em consequência do desenvolvimentismo, da modernização da agricultura que os excluía. $\mathrm{O}$ advento da hidrelétrica de Passo Real colocou em cena o grupo dos "afogados", que também lutava contra a perda das suas terras, mesmo que por outros motivos. Nessa luta, sessenta famílias não contempladas ou que tiveram o reconhecimento de seus direitos negados pelo Incra ocuparam a fazenda Annoni, com os "sem-terra", formando um acampamento em meados de 1970.

A “indústria dos movimentos sociais" encontra substratos em dois SMO ou frames que se aproximam por meio do que os segundos chamam de master frames (SNOW; BENFORD, 1992). O conceito de master frame funciona da mesma forma que oframe, todavia é mais genérico, catalisador e acontece em maior escala. A mudança de escala implica a variedade maior de recursos e objetivos inter-relacionados. Dessa forma, o potencial aglutinador de um master frame depende de variáveis, como capacidade de atribuição, fidelidade ou centralidade narrativa e credibilidade empírica ou comensurabilidade experimental.

Geograficamente, os caminhos dos sem-terra e dos afogados se aproximaram na antiga Fazenda Sarandi. Já na perspectiva da mobilização social, a luta pela terra corresponde ao master frame, que identifica esses dois movimentos. Observando o potencial aglutinador do master frame a partir dos 
pontos citados, pode-se afirmar que a luta pela terra seria o master frame, que identifica os afogados e os sem-terra. No tocante à atribuição, ambos identificam a modernização ou industrialização e concentração fundiária como problemas que teriam como solução a reforma agrária. No viés da articulação, o fato de ambos serem expropriados por uma política desenvolvimentista confere fidelidade e credibilidade para uma narrativa de sofrimento e luta que condiz com a realidade empírica daqueles que, por um ou outro motivo, terminaram acampados, conformando esse quadro.

Essas colocações, mesmo que tratadas sumariamente, servem para explicar o ciclo de protestos inaugurado a partir de meados de 1960, iniciando um novo master frame a partir da luta pela democracia ou contra a ditadura. No tocante ao meio rural, não obstante a influência desse quadro, a luta pela terra passou a ser o master frame que identificou os sem-terra e afogados. O predomínio do elemento terra sobre o elemento água é compreensível tanto pela credibilidade empírica, pois se trata de terra que se perdeu com a inundação pela hidrelétrica, quanto pelo fato de o master atribuir à terra, ou à sua má distribuição, a causa e solução para o problema social brasileiro. Dessa forma, o master frame influenciou no repertório dos movimentos, tornando a ocupação de terras a sua marca registrada. Essa tática que havia minguado em consequência dos "anos de chumbo" retornaria em razão de um quadro de oportunização política a partir do que a luta pela terra pode ser compreendida como um master frame, que aglutinou grupos e orientou um repertório que tinha nas ocupações a principal ação. Os anos de chumbo, que vamos considerar aqui com vistas à publicação e suspensão do Ato Institucional n 5 (AI 5), compreendem um período em que a luta pela terra sofreu forte repressão e avançou menos em termos de conquistas em comparação a outros períodos.

A retomada da luta pela terra tomou novo impulso no final de 1970, a partir de um cenário que vai ao encontro do que Sidney Tarrow (2009) define como "estrutura de oportunidades políticas" (EOP), visando compreender como as demandas de grupos são manifestadas diante de um 
cenário oportuno que deu origem a confrontos políticos. $\mathrm{O}$ autor sustenta que, num cenário de oportunização, “o confronto político surge como uma reação a mudanças nas oportunidades e restrições políticas em que os participantes reagem a uma variedade de incentivos materiais e ideológicos, partidários ou baseados no grupo, de longa duração ou episódicos" (TARROW, 2009).

No entanto, um cenário de oportunidades não significa necessariamente que confrontos políticos ocorram. Mesmo diante das demandas dos grupos, pontuais ou estruturais, há que distinguir-se "potencial de mobilização" de "ação de fato". O primeiro representa o estado de latência do confronto, ao passo que o segundo representa a mobilização efetiva que o promove. Nesse sentido, Tarrow (2009) apresenta cinco aspectos observados de forma a perceber-se como essa passagem de potencial em ação pode acontecer de maneira geral: “1) abertura do acesso à participação para novos atores; 2) evidência de realinhamento político no interior do sistema; 3) presença de aliados influentes; 4) divisões emergentes no interior da elite; 5) declínio na capacidade do estado de reprimir dissidências."

Resgatando a história do Brasil, esse quadro de oportunização corresponde ao período em que o poder de repressão do Estado foi aos poucos diminuindo em relação aos chamados anos de chumbo, auge do período militar. A revogação do AI 5 (outubro de 1978), a Lei da Anistia (agosto de 1979) e o fim do bipartidarismo (novembro de 1979) permitiram a volta dos exilados políticos ao país de origem, reforçando o ativismo das diversas causas sociais, promovendo a divisão das elites e acarretando o enfraquecimento das oligarquias, o realinhamento político e o fortalecimento da sociedade civil.

De acordo com o panorama histórico apresentado, há de considerar-se que o enfraquecimento do regime militar, não obstante as lutas pela redemocratização, passa pela dificuldade econômica do final do ciclo desenvolvimentista brasileiro (1930-1980). Os seguidos anos de crescimento e as iniciativas de modernização (agricultura e projetos de grande escala) 
sustentadas por financiamentos exteriores ficaram comprometidas em razão da crise do petróleo de 1979, que afetou o mundo inteiro, e no Brasil inaugurou um novo período econômico de crise. Dessa forma, o regime ditatorial já não contava com a pujança econômica para contrabalançar a repressão. A partir daí configurou-se um período de abertura política que ganhou espaço na participação de novos atores, ficando a repressão mais fraca.

Concentrando a discussão na luta pela terra no campo político-institucional no estado do Rio Grande do Sul, são notórios os trabalhos da Assembleia Legislativa na investigação parlamentar da Fazenda Sarandi (1979) e na questão das barragens em 1983. Há que registrar-se outro importante realinhamento político, a criação do Partido dos Trabalhadores (PT), que passou a caminhar ao lado dos movimentos sociais.

Quanto à luta pela terra propriamente dita, o norte gaúcho esboçou, no final da década de 1970, o ressurgimento das mobilizações. O ambiente de oportunização política reascendeu a questão indígena no município de Nonoai, local onde os agricultores intrusaram as terras indígenas desde 1960. O movimento indígena passou a utilizar a tática da intimidação e da expulsão das famílias de agricultores, passando a integrar-se à massa dos sem-terra, ocupando a reserva florestal da Fazenda Sarandi em meados de 1978, o que passou a ser seguido por outras famílias. Do excedente de famílias que não encontraram espaço na Fazenda Sarandi no momento, originou-se o acampamento da Encruzilhada Natalino, em 8 de dezembro de 1980, estendendo-se até 1983.

Em meio ao cenário de oportunização, foram fundados, definitivamente, dois movimentos sociais de expressão na luta pela terra, o Movimento dos Trabalhadores Rurais Sem Terra (MST) e o Movimento dos Atingidos por Barragens (MAB). As ocupações de terras realizadas nos estados de Santa Catarina, Paraná, São Paulo, Mato Grosso do Sul e, sobretudo, Rio Grande do Sul resultaram na fundação do MST durante o I Encontro nacional do MST, realizado em 1984, em Cascavel-PR. A questão dos "afogados" do Passo Real e a divulgação de que a Eletrosul pretendia 
instalar 25 hidrelétricas na bacia do Uruguai contribuíram para a criação da Comissão Regional de Barragens (CRAB), em Concórdia-SC, em 1979, que passou a responder como MAB/Região Sul a partir de 1991, quando se oficializou o MAB durante o I Congresso Nacional dos Atingidos por Barragens em Brasília.

O cenário de oportunização política permitiu a articulação de pessoas e instituições, como intelectuais, setores de universidades, políticos e alas de partidos políticos, sindicatos combativos, organizações da sociedade civil - CNBB, OAB e ABI -, segmentos das igrejas Católica e Luterana, além de organizações internacionais, de forma que a luta pela terra, embora protagonizada pelos agricultores, contou com um importante suporte material e ideológico que ajudou a conformar os repertórios dos movimentos sociais de luta pela terra. Dessa forma, a formação da CRAB e, depois, do MAB tem nos afogados do Passo Real uma importante referência de estruturação. Os atingidos pela UHE Itaipu-PR também se aproximaram do MASTRO e de certa forma ajudaram na estruturação do MST, que tem nas ações do Master Encruzilhada Natalino e Annoni importantes elementos da sua formação.

A partir da aproximação dos sem-terra e dos afogados na luta pela terra, várias ações de ocupação, tanto a propriedades quanto a órgãos públicos, foram registradas nos anos seguintes. Em qualquer movimento social é difícil uma homogeneidade e as disputas internas também foram elementos marcantes dessa articulação. De qualquer forma, a Fazenda Annoni já representava um palco de luta pela terra com repercussão internacional, onde se aglutinaram os afogados e os sem-terra, evidenciando pontos comuns entre as diferentes demandas e as diferenças de interesses.

Desde o final do processo de reassentamento na Annoni, já num ambiente político mais democrático, os movimentos sociais seguiram trajetórias próprias, estabelecendo uma identidade de luta pela terra forjada ao longo do processo. James M. Jasper (2016) conceitua "movimentos sociais" como "esforços persistentes e intencionais para promover ou obstruir 
mudanças jurídicas e sociais de longo alcance, basicamente fora dos canais institucionais sancionados pelas autoridades". A persistência, assinalada por Jasper, diferencia movimento social de eventos isolados. A intencionalidade indica que um movimento social implica cultura e estratégia para promover as mudanças sociais e jurídicas pela via não institucional, para mencionar o próprio movimento, sem esquecer as relações com partidos políticos e grupos de interesses dos quais se diferiam. O governo brasileiro imprimiu uma política desenvolvimentista desde a década de 1930, porém, na década de 1950, na Revolução Verde, tratou de modernizar a agricultura, estreitando a fronteira agrícola e promovendo conflitos entre indígenas e agricultores, depois os projetos de grande escala que expropriavam pela inundação, começando a registrar-se mobilizações, mesmo que esparsas. Essa "mobilização" deu-se a partir de ciclos de confrontos em que os repertórios correspondem à intencionalidade de resistir e promover a mudança dessa realidade.

Foi nesse processo histórico que a intencionalidade e a persistência marcaram as mobilizações desde a década de 1950, convergiram para a criação do MST, em 1982, e MAB, em 1991. É possível considerar os movimentos sociais anteriores a essas datas, porém foi a partir desses momentos que a luta pela terra passou a contar com o protagonismo e a referência de forma persistente definitivamente, reforçando suas bandeiras específicas paralelas à identificação em torno da luta pela terra.

A complexidade da questão fundiária no Brasil, intercruzada por aspectos econômicos, culturais e políticos, fez emergir outros movimentos de expressão, como o Movimento dos Pequenos Agricultores (MPA) e o Movimento de Mulheres Camponesas (MMC), oriundos da mobilização no âmbito dos movimentos anteriores, mas que construíram suas bandeiras específicas e ampliaram o master frame da luta pela terra, encontrando amparo teórico-metodológico na perspectiva dos novos movimentos sociais (NMS). Num outro estágio de desenvolvimento, esses movimentos formalizaram sua articulação em 1993, por ocasião da I Conferência da Via 
Campesina, em Mons (Bélgica). Esse movimento de abrangência internacional reúne organizações camponesas de pequenos e médios produtores, mulheres rurais, comunidades indígenas, quilombolas, sem-terra, jovens rurais e trabalhadores agrícolas migrantes nos cinco continentes. Apesar da internacionalização, a Via Campesina representa uma continuidade das lutas de 1960, 1970, 1980, especialmente no que se refere aos eventos ocorridos no norte do Rio Grande do Sul.

A história dos movimentos e as lutas sociais descritas por Maria da Glória Gohn ganham novos atores e demandas neste início de século XXI, com destaque no avanço da luta e implementação de políticas públicas na saúde, educação, crédito e habitação rural. Seguindo a concepção gramsciana de hegemonia, mesmo que o Estado tenha permanecido condicionado aos interesses do capital, houve a concessão de algumas políticas sociais para os trabalhadores, fruto das lutas e mobilizações nas últimas três décadas. O processo histórico que originou os movimentos sociais de luta pela terra ainda contabiliza tanto refluxos, divisões internas e criminalizações quanto conquistas, como a chegada do PT ao governo federal. São momentos que impõem desafios, criam esperanças e geram frustrações, levando esses movimentos sociais a permanecer em constante atualização.

Como forma de registro da parte do processo até aqui apresentado, este livro foi pensado para contemplar questões contemporâneas distintas, agrupadas em três partes: "Representações do mundo rural"; "Conflitos pela terra"; "Pautas e políticas para o campo". Cada parte é formada por quatro capítulos que apresentam diferentes questões atuais segundo essas linhas respectivas.

Na primeira parte, "As representações do mundo rural", o texto de Humberto José da Rocha e Gerson de Lima Oliveira apresenta um resgate histórico-analítico da mobilização e organização dos atingidos por barragens na bacia do rio Uruguai a partir da trajetória do movimento dos atingidos por barragens (MAB), abrangendo o período dos anos 1970, da formação do movimento social até a atualidade, de forma a distinguir 
pautas, avanços e refluxos desse movimento em relação aos estágios do processo social no que diz respeito a barragens no sul do Brasil.

No segundo trabalho desse eixo temático, Jairo Bolter e Jaqueline Haas analisam a trajetória da Federação dos Trabalhadores na Agricultura Familiar da Região Sul do Brasil (Fetraf-Sul) no processo de organização e proposição de um projeto de desenvolvimento socialmente justo e economicamente sustentável para a agricultura familiar. O estudo compreende desde o início da articulação, década de 1980, até a atualidade, quando se faz presente em 18 estados brasileiros, compondo a Federação Nacional dos Trabalhadores e Trabalhadoras na Agricultura Familiar (Fetraf-Brasil) e se constituindo numa das principais organizações sociais da agricultura familiar existente no país. ${ }^{4}$

No terceiro trabalho deste grupo, Cleber José Bosetti discute a reforma agrária brasileira segundo nuanças do terreno discursivo. Nesse sentido apresenta elementos como redistribuição fundiária, desigualdade social, desemprego, precariedade da cidadania e problemas ambientais enquanto partes da narrativa dos movimentos sociais pela reforma agrária. Centrando a análise no Movimento dos Trabalhadores Rurais Sem Terra (MST), o autor resgata esse processo, identifica as mudanças em relação aos contextos sociais de forma a chegar nos dias atuais, em que a proposição de um projeto alternativo de desenvolvimento rural tem na agroecologia uma de suas principais bandeiras discursivas.

Fechando o primeiro bloco, o trabalho de Valdete Boni aborda a questão da mulher no campo, tendo como foco o Movimento de Mulheres Camponesas (MMC). Registrando a recente criação oficial do movimento (2004), a autora apresenta os temas da segurança e soberania alimentar na perspectiva de discurso e prática do MMC por meio das ações contra as empresas de sementes transgênicas e recuperação de sementes crioulas.

4 A partir de maio de 2016 a FETRAF foi transformada na Confederação Nacional dos Trabalhadores e Trabalhadoras da Agricultura Familiar (CONTRAF-BRASIL). Seguiremos a denominação FETRAF por estarmos analisando o período que antecede esta alteração. 
De forma conjunta, o texto analisa o movimento de mulheres camponesas enquanto movimento feminista com base no debate sobre segurança e soberania alimentar.

O segundo eixo temático deste livro traz como tema "Conflitos pela terra” no sul do Brasil. O módulo é aberto por Algacir José Rigon, Vinicius Piccin Dalbianco e José Guilherme Franco Gonzaga, que apresentam um panorama da evolução da luta pela terra, tendo como ponto de referência o MST tanto pelo pioneirismo quanto pela continuidade das lutas. Nessa perspectiva, ao apresentar a evolução das estratégias e demandas do MST, o texto marca diferentes momentos de luta pela terra no sul do Brasil, que possibilita uma visão do processo social a partir do protagonismo do MST.

O trabalho de João Carlos Tedesco, Gean Zimermann da Silva e Alex Antônio Vanin apresenta a luta pela terra na perspectiva da disputa entre indígenas e agricultores no norte do Rio Grande do Sul. Os autores analisam um processo histórico em que as disputas tendem a assumir contornos favoráveis tanto para agricultores quanto para indígenas, segundo as ações de mobilização de ambos em relação aos respectivos contextos sociais. A modernização da agricultura, as orientações ideológicas e a Constituição de 1988 são elementos que parecem desequilibrar momentaneamente em favor de determinado grupo em diferentes estágios desse processo.

O trabalho de Leonel Piovezana, Giovana Didoné Piovezana e Maria de Lourdes Bernartt segue a mesma direção, porém localiza a discussão no Oeste catarinense. Tendo também a questão indígena como referência, os autores resgatam o processo de ocupação desse espaço, relacionando a outros movimentos sociais de forma a possibilitar uma compreensão expandida não só da questão indígena, mas também do processo histórico em seu conjunto, para a compreensão da trajetória conflituosa e da possibilidade da configuração de uma "terra de ninguém" para uma "terra sem males".

Fechando essa parte do livro, o texto de Heron Lisboa Oliveira e Edla Eggert mantém a linha de análise, entretanto apresenta o conflito pela terra na perspectiva das comunidades negras rurais. Localiza a discussão em 
duas comunidades remanescentes de antigos quilombolas no norte do Rio Grande do Sul. Os autores apresentam as ideias de dádiva e a reciprocidade enquanto elemento de coesão, permanência e ampliação de territórios disputados num campo que compreende múltiplos atores e interesses historicamente constituídos.

O terceiro eixo temático refere-se às "Pautas e políticas para o campo" tanto do que já foi conquistado pelas mobilizações quanto do que ainda representa demandas a serem alcançadas. Abrindo este bloco, Cátia Grisa e Jonas José Seminotti analisam as demandas da agricultura familiar a partir da pauta de reivindicações da Fetraf-Brasil entre 2005 e 2015. Abordadas em dimensão histórica, as pautas não só resgatam um processo social relativo à própria agricultura familiar, como também expressam um conjunto de demandas em termos de políticas públicas e demais ações do Estado.

Seguindo na mesma linha, o trabalho apresentado por Jonas José Seminotti, Catia Grisa e Roniere dos Santos Fenner aprofunda a discussão, concentrando a análise no Programa Nacional de Fortalecimento da Agricultura Familiar (Pronaf) e no Programa Nacional de Educação do Campo (Pronacampo). O texto permite compreender como as duas linhas representam conquistas da agricultura familiar e elementos de constituição e fortalecimento das políticas públicas para o campo.

A educação é tema também do trabalho de Tânia Mara de Bastiani. Tendo por base as concepções, tanto abordadas pelas políticas públicas de educação do campo, quanto do Movimento dos Trabalhadores Rurais Sem Terra (MST) para as escolas dos assentamentos, o texto apresenta um comparativo no que diz respeito aos conteúdos curriculares, entre a escola frequentada por crianças e adolescentes do Assentamento Madre Terra em São Gabriel-RS até o final de 2013 e a escola idealizada pelos assentados para atuar dentro do assentamento, a partir de 2014.

Por fim, o trabalho de Willian Simões traz a questão da educação do campo para além de sua constituição política institucional, uma vez que 
o autor apresenta uma síntese de conquistas e desafios, compreendendo um estado da arte sobre essa temática no sul do Brasil.

Com esse conjunto de trabalhos organizados nos três eixos temáticos, procura-se oferecer diferentes perspectivas de discussão sobre a questão rural na contemporaneidade. A complexidade dessa questão requer especificidades, concomitantemente relacionadas a contextos mais amplos, que requerem análises multidisciplinares empreendidas de forma multiescalar. Eis um cenário de pesquisa para o rural da atualidade.

\section{REFERÊNCIAS}

GOHN, Maria da Gloria. História dos movimentos e lutas sociais: a construção da cidadania dos brasileiros. 7. ed. São Paulo, SP: Loyola, 2012.

JASPER, James, M. Protesto: uma introdução aos movimentos sociais. Rio de Janeiro: Zahar, 2016.

MCCARTHY, John D.; ZALD, Mayer N. Resource mobilization and social movements: a partial theory. The American Journal of Sociology, Vol. 82, n. 6, May, 1977, p. 1212-1241.

SNOW, David A.; BENFORD, Robert D. "Master frames and cycles of protest". In: MORRIS, A.; MUELLER, C. M. (Org.). Frontiers in social movement theory. London: Yale University Press, 1992, p. 133-55.

TARROW, Sidney. O poder em movimento: movimentos sociais e confrontos políticos. Petrópolis: Vozes, 2009.

TILLY, Charles. From mobilization to revolution. Reading: Addison-Wesley, 1977. 